\title{
Association between Self-Perceived Health, Physical Activity, and BMD in Aging Men and Women
}

\author{
Taru Tervo ${ }^{*, 1}$, Peter Nordström ${ }^{1,2}$ and Anna Nordström ${ }^{1,3}$ \\ ${ }^{I}$ Department of Surgical and Perioperative Sciences, Sports Medicine, Umeå University, Umeå, Sweden \\ ${ }^{2}$ Department of Community Medicine and Rehabilitation, Geriatrics, Umeå University, Umeå, Sweden \\ ${ }^{3}$ Department of Community Medicine and Rehabilitation, Rehabilitation Medicine, Umeå University, Umeå, Sweden
}

\begin{abstract}
The association between general health and bone mineral density (BMD, $\left.\mathrm{g} / \mathrm{cm}^{2}\right)$ is not well studied. The purpose of this study was therefore to examine the relationships between BMD, self-perceived health, and lifestyle factors in a well-defined cohort of middle-aged men and women. The cohort studied consisted of 1595 women and men with a mean age of 57 years at baseline (range 30-74 yr), who completed a comprehensive health survey within the Västerbotten Intervention Project. BMD was measured at the femoral neck and lumbar spine a mean of 5 years later using Dual Energy X-ray absorptiometry. After adjusting for age, weight, sex, and follow-up time, self-perceived health $($ Beta $=0.08$, $\mathrm{p}<0.001)$, training $($ Beta $=0.11, \mathrm{p}<0.001)$, snow shoveling $($ Beta $=0.07, \mathrm{p}=0.001)$, and smoking more than 15 cigarettes per day $($ Beta $=-0.05, \mathrm{p}=0.04)$ were found to be related to femoral neck BMD. Only self-perceived health, age, and weight were found to be related to spine BMD. Self-perceived health was also found to be related to some of the lifestyle factors that were significantly related to BMD, such as training $(r=0.14, p<0.001)$ and snow shoveling $($ Beta $=0.15$, $\mathrm{p}<0.001$ ). In summary, several lifestyle factors related to self-perceived health were also found to be related to bone mineral density in a well-defined cohort of middle-aged men and women.
\end{abstract}

Keywords: Bone mineral density, self perceived health, physical activity.

\section{INTRODUCTION}

Osteoporosis is a large public health problem and its prevalence is expected to rise due to the aging population [1]. It is defined as a skeletal disorder that is characterized by reduced bone mass and microstructural deterioration of bone tissue that increases the risk of low-trauma fractures [2]. These fractures are associated with a high degree of morbidity and mortality, resulting in a heavy burden both on the individual and the society [3].

Low bone mineral density (BMD) has been identified as a strong risk factor for fractures in both men and women [4]. Furthermore, there are both internal and external risk factors that have shown to impact bone mass. Internal factors like old age, female sex and parental hip fracture cannot be modified [5-6]. However, external factors like nutrition, physical inactivity and smoking can be modified [5-9].

One important lifestyle factor that affects bone mass is physical activity. Positive effects of weight bearing, dynamic training on bone density gain have been observed in interventional studies of children and adolescents [10-16]. Some studies have also shown an association between weightbearing physical activity and BMD in middle-aged women and men [17-21]. These studies have reported either a higher BMD in physically active pre- and postmenopausal women

*Address correspondence to this author at the Department of Surgical and Perioperative Sciences, Sports Medicine, Umeå University, Umeå, Sweden; Tel: +46-90-7865000; Fax: +46-90-135692;

E-mail: taru.tervo@idrott.umu.se compared to inactive women in this same age group [17-21] or less bone loss in physically active women compared to inactive women [21, 22]. Only a few studies have investtigated the association between physical activity and BMD in non-athletic middle-aged men $[23,24]$. The few studies that have been performed have shown that an active life style is associated with a higher BMD and less bone loss [23, 24].

Another lifestyle factor that has been found to be associated with low bone mass is smoking [25], which influences BMD through the direct effects that nicotine has on osteoblast proliferation and ostepontin synthesis [26].

Some of these lifestyle factors, such as physical activity, have been found to be associated with decrease in self-rated general health status [27, 28]. However, to our knowledge, the association between self-perceived health, lifestyle factors, and BMD has not previously studied in a large cohort of middle-aged women and men. Consequently, the aim of this study was to investigate the association between BMD, self-perceived health, and various lifestyle factors in a large cohort of middle-aged women and men.

\section{MATERIAL AND METHODS}

\section{Subjects}

The Västerbotten Intervention Program (VIP) [29] is a community-based project focused on examining the risk of cardiovascular disease and diabetes in middle-aged individuals. The study began in 1985 in the county of Västerbotten [29]. In short, all residents aged 40, 50, and 60 years are invited to obtain a standardized health examination at a pri- 
mary care center in Västerbotten. Blood pressure and blood lipid levels are measured, and an oral glucose tolerance test is performed. All participants are also asked to answer a comprehensive questionnaire that includes questions about lifestyle and psychosocial conditions. Patients are also asked to donate blood for future research.

At the Sports Medicine Unit, bone mineral density and body composition have been measured using dual energy Xray (DEXA) since 1991. Most of the subjects have had their BMD measured because of previous fractures or because they have had risk factors for low BMD. By the end of 2006, DEXA scans had been performed on 4333 women and 2320 men.

A total of 1,595 subjects (1,389 women and 206 men) that first obtained the VIP evaluation and later had their BMD measured at the femoral neck and lumbar spine were included into the present study.

From the questionnaire used at the VIP investigation, self-perceived health was coded as 0 (worse than other subjects of the same age), 1 (equal to other subjects of the same age), and 2 (better than other subjects of the same age). Diabetes was coded as 0 (no) or 1 (yes). Current smoking was coded as 0 (no) or 1 (yes), and as 0 (smoking less than 15 cigarettes per day), and 1 (smoking more than 15 cig-arettes per day). Physical activity in training clothes during the preceding three months was coded as 0 (not regularly), 1 (12 times a week), and 2 (at least 2 times per week). Bicycling and walking associated with at least some sweating was coded 0 (2 times a month or less), 1 (3-4 times a month), and 2 (at least 2 times a week). Snow shoveling, berry/mushroom picking, and dancing were coded as 0 (never), 1 (at most 1 time per week), and 2 (at least 1 time per week).

\section{Measurements of BMD}

BMD $\left(\mathrm{g} / \mathrm{cm}^{2}\right)$ was measured using Dual Energy X-ray Absorptiometry (DXA). From 1991 until 1998 a Lunar DPX-L was used and from 1998 and onward a Lunar-IQ was used (GE-Lunar, GE Healthcare, USA). The coefficient of variation $(\mathrm{CV}, \mathrm{SD} /$ mean) was determined by scanning one person seven times, with repositioning between every scan. Accordingly, the CV values were approximately $1 \%$ for the different estimates of femoral neck BMD and lumbar spine. The equipment was calibrated each day using a standardized phantom to detect drifts in the measurements. The equipment was also evaluated regularly using a spine phantom. No drifts in BMD were detected. The same technician performed more than $90 \%$ of all the scans.

Height was measured using a wall-mounted stadiometer and weight was measured to the nearest kilogram using a digital scale. Body mass index was calculated as weight/ height ${ }^{2} \mathrm{~kg} / \mathrm{m}^{2}$.

All participants provided informed consent and the Ethical Committee of the Medical Faculty of Umeå University approved the study protocol.

\section{Statistics}

All statistical analyses were performed using SPSS (version 17: SPSS, Chicago, IL). The independent associations between lifestyle factors and BMD were examined using linear regression using age, weight, sex, and time between VIP and BMD measurement as the independent variables. The associations between self-perceived health and several lifestyle factors were investigated using partial correlation analysis after adjusting for age. All data are expressed as mean \pm standard deviation. All p-values $<0.05$ were considered to be statistically significant.

\section{RESULTS}

In the present study, 1,595 women and men were included from the VIP investigation who were evaluated between 1993 and 2006 Their mean age at baseline was 57 years (range 30-74). The mean follow-up time was 1931 days (range 1-5,019 days) between the VIP investigation and the BMD measurements in the femoral neck and spine. The baseline physical characteristics, self-perceived health status, physical activity habits, and other lifestyle characteristics of the cohort are shown in Table $\mathbf{1 .}$

Table 1. Baseline Characteristics of the Cohort Studied

\begin{tabular}{|c|c|}
\hline Sex - no. $(\%)$ & \\
\hline Women & $1,389(87)$ \\
\hline Men & $206(13)$ \\
\hline Age - years \pm SD & $57.5 \pm 8.4$ \\
\hline Weight $-\mathrm{kg} \pm \mathrm{SD}$ & $70.1 \pm 12.6$ \\
\hline Height $-\mathrm{cm} \pm \mathrm{SD}$ & $165 \pm 8$ \\
\hline $\mathrm{BMI}-\mathrm{kg} / \mathrm{m}^{2} \pm \mathrm{SD}$ & $25.6 \pm 4.2$ \\
\hline Diabetes - no. $(\%)$ & $22(1.4)$ \\
\hline Femoral neck BMD $-\mathrm{g} / \mathrm{cm}^{2} \pm \mathrm{SD}$ & $0.87 \pm 0.14$ \\
\hline Lumbar BMD $-\mathrm{g} / \mathrm{cm}^{2} \pm \mathrm{SD}$ & $1.06 \pm 0.19$ \\
\hline \multicolumn{2}{|l|}{ Physical activity - no. (\%) } \\
\hline No regular physical activity & $753(69)$ \\
\hline 1-2 times per week & 209 (19) \\
\hline At least 2 times per week & $129(12)$ \\
\hline \multicolumn{2}{|l|}{ Bicycling - no. $(\%)$} \\
\hline 2 times per month or less & $542(40)$ \\
\hline 3-4 times per month & $194(14)$ \\
\hline At least 2 times per week & $626(46)$ \\
\hline \multicolumn{2}{|l|}{ Walking - no. $(\%)$} \\
\hline 2 times per month or less & $230(15)$ \\
\hline 3-4 times per month & $292(19)$ \\
\hline At least 2 times per week & $1,014(66)$ \\
\hline \multicolumn{2}{|l|}{ Snow shoveling - no. $(\%)$} \\
\hline Never or seldom & $407(28)$ \\
\hline Ever month & $397(28)$ \\
\hline Every week & $636(44)$ \\
\hline \multicolumn{2}{|l|}{ Berry/mushroom picking - no. $(\%)$} \\
\hline Never or seldom & $203(13)$ \\
\hline Ever month & $522(35)$ \\
\hline Every week & $776(52)$ \\
\hline
\end{tabular}


(Table 1) Contd.....

\begin{tabular}{|c|l|}
\hline Dancing - no. (\%) & \\
\hline Never or seldom & $858(62)$ \\
\hline Every month & $397(29)$ \\
\hline Ever week & $129(9)$ \\
\hline Self-perceived health - no. (\%) & \\
\hline Worse than other subjects of the same age & $224(14)$ \\
\hline Equal to other subjects of the same age & $1,133(73)$ \\
\hline Better than other subjects of the same age & $188(12)$ \\
\hline
\end{tabular}

The independent associations between various lifestyle factors and BMD are shown in Table 2. Self-perceived health was found to have an independent significant positive

Table 2. Independent Associations between Lifestyle Factors and $\mathrm{BMD}^{\dagger}$

\begin{tabular}{|l|c|c|}
\hline & $\begin{array}{c}\text { Femoral neck } \\
\text { BMD }\end{array}$ & $\begin{array}{c}\text { Lumbar spine } \\
\text { BMD }\end{array}$ \\
\hline \hline Self-perceived health & $0.08^{* * *}$ & $0.05^{*}$ \\
\hline Smoking & -0.02 & -0.01 \\
\hline $\begin{array}{l}\text { Smoking more than } 15 \\
\text { cigarettes a day }\end{array}$ & $-0.05^{*}$ & 0.00 \\
\hline Physical activity & $0.11^{* * *}$ & 0.05 \\
\hline Snow shoveling & $0.07^{* *}$ & 0.03 \\
\hline Cycling & 0.03 & -0.02 \\
\hline Walking & 0.03 & 0.02 \\
\hline Berry/mushroom picking & 0.03 & 0.02 \\
\hline Dancing & 0.01 & 0.01 \\
\hline $\begin{array}{l}* \\
\text { "Results are adjusted for age, weight, sex, and time elapsed between VIP and BMD } \\
\text { measurements. }\end{array}$ &
\end{tabular}

association with both femoral neck BMD (Beta $=0.08$, $\mathrm{p}=0.000$ ) and lumbar spine BMD (Beta $=0.05, \mathrm{p}=0.04)$. BMD of the femoral neck was also associated with physical activity $(B e t a=0.11, p=0.000)$ and snow shoveling $(B e t a=0.07$, $\mathrm{p}=0.001$ ). In contrast, smoking more than 15 cigarettes a day showed a negative association with BMD of the femoral neck (Beta $=-0.05, \mathrm{p}=0.04)$. When the independent associations between various lifestyle factors and BMD data was analyzed separately for men and women, smoking more than 15 cigarettes a day showed a negative association (Beta $=$ $-0.05, \mathrm{p}=0.03)$ and snow shoveling showed an positive association with BMD of the femoral neck in women (Beta $=0.08$, $\mathrm{p}=0.002$ ). These results were not significant for men.

The independent association between self-perceived health and various lifestyle factors were investigated after adjusting for age (Table 3). Self-perceived health was found to be significantly associated with physical activity ( $\mathrm{r}=0.14$, $\mathrm{p}<0.001)$, snow shoveling $(\mathrm{r}=0.15, \quad \mathrm{p}<0.001)$, cycling $(\mathrm{r}=0.12, \mathrm{p}=0.001)$, and berry/mushroom picking $(\mathrm{r}=0.11$, $\mathrm{p}=0.002$ ).

Table 3. Independent Associations between Self-Perceived Health and Various Lifestyle Factors"

\begin{tabular}{|l|l|}
\hline & Self-perceived Health \\
\hline \hline Smoking more than 15 cigarettes a day & 0.02 \\
\hline Physical activity & $0.14^{* * *}$ \\
\hline Snow shoveling & $0.15^{* * *}$ \\
\hline Cycling & $0.12^{* * *}$ \\
\hline Walking & 0.02 \\
\hline Berry/mushroom picking & $0.11^{* *}$ \\
\hline Dancing & 0.07 \\
\hline $\begin{array}{l}* \text { Results are adjusted for age } \\
{ }^{* *} \mathrm{p}<0.01,{ }^{* * *} \mathrm{p}<0.001\end{array}$ &
\end{tabular}

The mean values for self-perceived health, physical activity, and BMD of the lumbar spine and femoral neck for different age groups are shown in Fig. (1). Both BMD and physical activity were lower in the older age groups, but no clear trend observed regarding the association between BMD and self-perceived health.

\section{DISCUSSION}

In this present study, we investigated the association between several lifestyle factors, self-perceived health, and

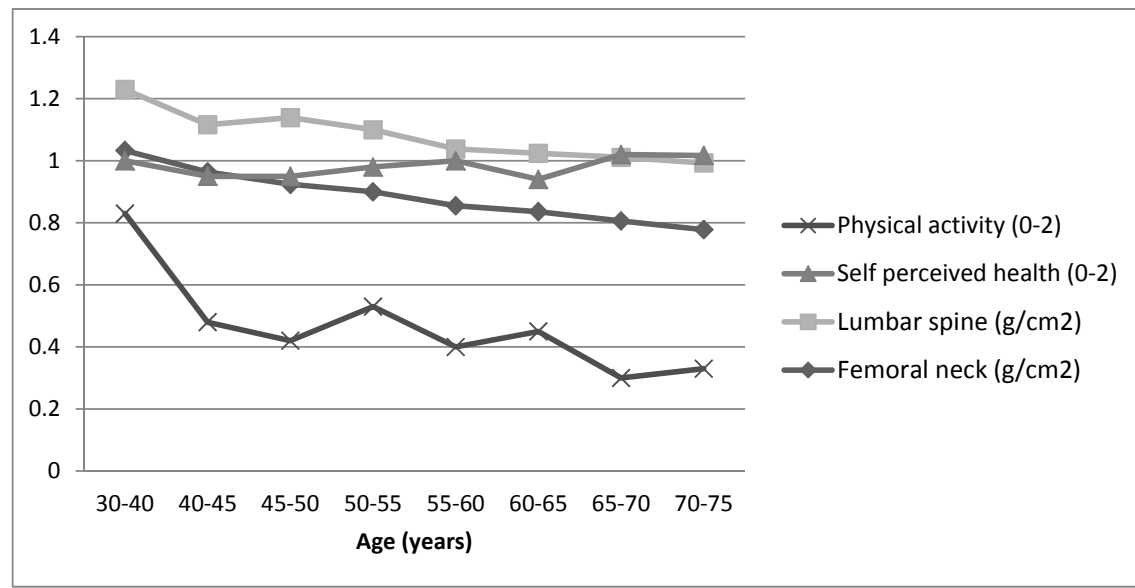

Fig. (1). Mean values for physical activity, self-perceived health, BMD of the lumbar spine, and femoral neck, stratified by age. 
BMD in a well-defined cohort of middle-aged women and men. We found that physical activity, self-perceived health status, snow shoveling, and smoking more than 15 cigarettes a day were significantly associated with BMD in the femoral neck after adjusting for the influence of confounding variables. In contrast, only age, weight and self-perceived health status were found to be associated with BMD in the lumbar spine. To our knowledge, this is the first study to evaluate the associations between self-perceived health, lifestyle factors, and BMD.

Approximately $50-70 \%$ of inter-individual variation in bone mass is determined by genetic factors, but the rest may be influenced by lifestyle factors, such as physical activity [30]. In the present study, physical activity, defined as physical activity performed in training clothes over the preceding three months, was found to be independently associated with BMD of the femoral neck, and this association was found to be stronger than the associations observed for the other lifestyle factors. Thus, activities like berry/mushroom picking, cycling, and dancing were not associated with BMD of the femoral neck or lumbar spine. On the other hand, snow shoveling was significantly associated with BMD in the femoral neck. These discrepancies might be due to differing osteogenic effects exerted by the activities that were investigated. It has been previously demonstrated in experimental studies that weight-bearing activities resulting in high strain in different directions of the skeleton are the most osteogenic types of physical activity [31, 32]. Furthermore, the effects are site-specific, i.e., only the site that is subjected to the loading is affected [33-35]. Presumably, snow shoveling and various activities performed in training clothes results higher strain on the femoral neck than activities such as walking and bicycling. These results have also been confirmed in clinical studies, in which high-impact training two to three times per week was found to increase BMD in premenopausal women; $[17,20,21]$ however, the effects of this type of physical activity on BMD in postmenopausal women are more modest [22, 36, 37]. Daly et al. studied the association between lifetime sport and leisure activity participation and bone characteristics in older men and showed that long-term regular participation in weightbearing sport and leisure activities was an important determinant of bone size, quality, and strength at the loaded sites [23]. In summary, it seems that physical activity characterized by weight loading at specific sites is associated with increased BMD in middle-aged women and men.

Self-perceived health was analyzed via a question in which the subjects were asked to grade their health as worse than, equal to, or better than other subjects of the same age. The results showed that self-perceived health was associated with physical activity, snow shoveling, cycling, and berry/ mushroom picking. Our results are in line with other studies showing that a physically active lifestyle is associated with better self-rated health perceptions [27, 38]. Self-perceived health was also associated with increased BMD of both the femoral neck and lumbar spine. One might speculate that a better self-perceived health status leads to a more physically active lifestyle, and therefore a higher BMD. It may also be that a physically active lifestyle leads to better self-perceived health. One previous population-based study investigated the association between self-rated health and BMD. As in our study, an association was found between poor health and low
BMD, however, this association was only observed among 50- to 79-year-old men [39].

In the present study both physical activity and BMD of the femoral neck were found to be lower in the older age groups than in the younger age groups. Since physical activity was also significantly associated with $\mathrm{BMD}$ of the femoral neck, it might be that some of the BMD loss in the femoral neck that occurred with increasing age was due to a reduced physical activity level. Nevertheless, given the cross-sectional design of the present study, conclusions cannot be made concerning causality. However, reduced physical activity levels in young athletes have shown to be related to faster loss of femoral neck BMD as compared to controls and as compared to BMD at other sites [40, 41].

The strengths of our study include a large, well-defined study cohort that included both women and men of different ages. One of the major limitations of our study is that the questions used at baseline concerning physical activity in training clothes did not specify the type of physical activity that was performed, i.e., whether the training was weightbearing or not. However, snow shoveling, a weight-bearing activity, was associated with higher BMD in the femoral neck, while non-weight-bearing activities, such as cycling and walking, were not associated with higher BMD in the femoral neck. Finally, it was a mean of five years between each subject answered the questionnaire and measured $\mathrm{BMD}$, and it is likely that a person's lifestyle might have changed during this time. Nevertheless, this would most likely have biased the regression estimates towards zero.

In summary, we found associations between self-perceived health, various lifestyle factors (such as physical activity level), and BMD in a well-defined cohort of middleaged men and women. If the findings of our cross-sectional study are also supported in follow-up studies the reported observations gives an important new knowledge of association between lifestyle factors and bone mass. This information may be used to make it easier to identify subjects with low BMD and then affect fracture prevention.

\section{ACKNOWLEDGEMENTS}

The present study was supported by funding from Västerbotten`s County Council.

\section{REFERENCES}

[1] Lane NE. Epidemiology, etiology, and diagnosis of osteoporosis. Am J Obstet Gynecol 2006; 194: S3-11.

[2] Genant HK, Cooper C, Poor G, et al. Interim report and recommendations of the World Health Organization task-force for osteoporosis. Osteoporos Int 1999; 10: 259-64.

[3] Strom O, Borgstrom F, Zethraeus N, et al. Long-term cost and effect on quality of life of osteoporosis-related fractures in Sweden. Acta Orthop 2008; 79: 269-80.

[4] Johnell O, Kanis JA, Oden A, et al. Predictive value of BMD for hip and other fractures. J Bone Miner Res 2005; 20: 1185-94.

[5] Liu H, Paige NM, Goldzweig CL, et al. Screening for osteoporosis in men: a systematic review for an American College of Physicians guideline. Ann Intern Med 2008; 148: 685-701.

[6] SBU. Osteoporosis, Prevention, Diagnosis and Treatment. In SBU 2003.

[7] Tatara MR. Neonatal programming of skeletal development in sheep is mediated by somatotrophic axis function. Exp Physiol 2008; 93: 763-72. 
[8] Tatara MR, Sliwa E, Krupski W. Prenatal programming of skeletal development in the offspring: effects of maternal treatment with beta-hydroxy-beta-methylbutyrate (HMB) on femur properties in pigs at slaughter age. Bone 2007; 40: 1615-22.

[9] Fewtrell MS, Williams JE, Singhal A, et al. Early diet and peak bone mass: 20 year follow-up of a randomized trial of early diet in infants born preterm. Bone 2009; 45: 142-9.

[10] Morris FL, Naughton GA, Gibbs JL, et al. Prospective ten-month exercise intervention in premenarcheal girls: positive effects on bone and lean mass. J Bone Miner Res 1997; 12: 1453-62.

[11] Bradney M, Pearce G, Naughton G, et al. Moderate exercise during growth in prepubertal boys: changes in bone mass, size, volumetric density, and bone strength: a controlled prospective study. J Bone Miner Res 1998; 13: 1814-21.

[12] MacKay HA, Petit MA, Schutz RW, et al. Augmented trochanteric bone mineral density after modified physical education classes:a randomized school-based intervention study in prepubescent and early pubecent children. J Pediatr 2000; 136: 156-62.

[13] Fuchs RK, Bauer JJ, Snow CM. Jumping improves hip and lumbar spine bone mass in prepubescent children: a randomized controlled trial. J Bone Miner Res 2001; 16: 148-56.

[14] Snow-Harter C, Bouxsein ML, Lewis BT, et al. Effects of resistance and endurance exercise on bone mineral status of young women: a randomized exercise intervention trial. J Bone Miner Res 1992; 7: 761-9.

[15] Weeks BK, Young CM, Beck BR. Eight months of regular inschool jumping improves indices of bone strength in adolescent boys and girls: the POWER PE study. J Bone Miner Res 2008; 23: 1002-11.

[16] Bailey DA, McKay HA, Mirwald RL, et al. A six-year longitudinal study of the relationship of physical activity to bone mineral accrual in growing children: the university of Saskatchewan bone mineral accrual study. J Bone Miner Res 1999; 14: 1672-9.

[17] Heinonen A, Kannus P, Sievanen H, et al. Randomised controlled trial of effect of high-impact exercise on selected risk factors for osteoporotic fractures. Lancet 1996; 348: 1343-7.

[18] Vainionpaa A, Korpelainen R, Leppaluoto J, et al. Effects of highimpact exercise on bone mineral density: a randomized controlled trial in premenopausal women. Osteoporos Int 2005; 16: 191-7.

[19] Winters-Stone KM, Snow CM. Site-specific response of bone to exercise in premenopausal women. Bone 2006; 39: 1203-9.

[20] Winters KM, Snow CM. Detraining reverses positive effects of exercise on the musculoskeletal system in premenopausal women. $\mathrm{J}$ Bone Miner Res 2000; 15: 2495-503.

[21] Uusi-Rasi K, Sievanen H, Pasanen M, et al. Influence of calcium intake and physical activity on proximal femur bone mass and structure among pre- and postmenopausal women. A 10-year prospective study. Calcif Tissue Int 2008; 82: 171-81.

[22] Brooke-Wavell K, Jones PR, Hardman AE. Brisk walking reduces calcaneal bone loss in post-menopausal women. Clin Sci (Lond) 1997; 92: 75-80.

[23] Daly RM, Bass SL. Lifetime sport and leisure activity participation is associated with greater bone size, quality and strength in older men. Osteoporos Int 2006; 17: 1258-67.
[24] Nguyen TV, Center JR, Eisman JA. Osteoporosis in elderly men and women: effects of dietary calcium, physical activity, and body mass index. J Bone Miner Res 2000; 15: 322-31.

[25] Broussard DL, Magnus JH. Risk assessment and screening for low bone mineral density in a multi-ethnic population of women and men: does one approach fit all? Osteoporos Int 2004; 15: 349-60.

[26] Walker LM, Preston MR, Magnay JL, et al. Nicotinic regulation of c-fos and osteopontin expression in human-derived osteoblast-like cells and human trabecular bone organ culture. Bone 2001; 28: 603-8.

[27] Sodergren M, Sundquist J, Johansson SE, et al. Physical activity, exercise and self-rated health: a population-based study from Sweden. BMC Public Health 2008; 8: 352

[28] Norman A, Bellocco R, Vaida F, et al. Total physical activity in relation to age, body mass, health and other factors in a cohort of Swedish men. Int J Obes Relat Metab Disord 2002; 26: 670-5.

[29] Weinehall L, Hallgren CG, Westman G, et al. Reduction of selection bias in primary prevention of cardiovascular disease through involvement of primary health care. Scand J Prim Health Care 1998; 16: 171-6.

[30] Eisman JA. Genetics of osteoporosis. Endocr Rev 1999; 20: 788 804.

[31] Robling AG, Hinant FM, Burr DB, et al. Improved bone structure and strength after long-term mechanical loading is greatest if loading is separated into short bouts. J Bone Miner Res 2002; 17: $1545-54$

[32] Lanyon LE. Control of bone architecture by functional load bearing. J Bone Miner Res 1992; 7 Suppl 2: S369-75.

[33] Fredericson M, Chew K, Ngo J, et al. Regional bone mineral density in male athletes: a comparison of soccer players, runners and controls. Br J Sports Med 2007; 41: 664-8; discussion 668.

[34] Heinonen A, Oja P, Kannus P, et al. Bone mineral density in female athletes representing sports with different loading characteristics of the skeleton. Bone 1995; 17: 197-203.

[35] Nordstrom A, Hogstrom M, Nordstrom P. Effects of different types of weight-bearing loading on bone mass and size in young males: A longitudinal study. Bone 2008; 42 (3): 565-71.

[36] Bassey EJ, Ramsdale SJ. Weight-bearing exercise and ground reaction forces: a 12-month randomized controlled trial of effects on bone mineral density in healthy postmenopausal women. Bone 1995; 16: 469-76.

[37] Grove KA, Londeree BR. Bone density in postmenopausal women: high impact vs. low impact exercise. Med Sci Sports Exerc 1992; 24: $1190-4$

[38] Okano G, Miyake H, Mori M. Leisure time physical activity as a determinant of self-perceived health and fitness in middle-aged male employees. J Occup Health 2003; 45: 286-92.

[39] Magnus JH, Broussard DL. Can self-rated health identify US women and men with low bone mineral density? A cross-sectional population study. Gend Med 2008; 5: 246-58.

[40] Valdimarsson O, Alborg HG, Duppe H, et al. Reduced training is associated with increased loss of BMD. J Bone Miner Res 2005; 20: 906-12.

[41] Tervo T, Nordstrom P, Neovius M, et al. Constant adaptation of bone to current physical activity level in men: a 12-year longitudinal study. J Clin Endocrinol Metab 2008; 93: 4873-9. 